Pacific Journal of Mathematic 


\title{
A NON-COMPACT KREIN-MILMAN THEOREM
}

\author{
D. K. OATES
}

This paper describes a class of closed bounded convex sets which are the closed convex hulls of their extreme points. It includes all compact ones and those with the positive binary intersection property.

Let $K$ be a closed bounded convex subset of a Hausdorff locally convex linear topological space $F$. Denote by $E K$ the extreme points of $K$, by co $E K$ their convex hull and let co $E K$ be its closure. We are interested in showing when

$$
K=\overline{\mathrm{co}} E K \text {. }
$$

The principal known results are the following:

THEOREM 1.1. If either

(a) $K$ is compact;

or (b) $K$ has the positive binary intersection

property;

$$
\text { then } K=\overline{\mathrm{co}} E K \text {. }
$$

Case (a) is the Krein-Milman Theorem [3, p. 131]. Case (b) was proved by Nachbin in [6], and he poses in [5, p. 346] the problem of obtaining a theorem of which both (a) and (b) are specializations. This is answered by Theorem 4.2. For the whole of this paper, $S$ is a Stonean (extremally disconnected compact Hausdorff) space. ${ }^{1}$

A simplified version of Theorem 4.2 reads as follows:

THEOREM 1.2. Let $X$ be a normed linear space. Then any norm-closed ball in the space $\mathfrak{B}(X, C(S))$ of continuous linear operators from $X$ to $C(S)$ is the closure of the conver hull of its extreme points in the strong neighborhood topology.

The result concerning the unit ball of a dual Banach space in its weak*-topology and that concerning the unit ball in $C(S)$ in its norm topology are special cases of Theorem 1.2.

A sublinear function $P$ from a vector space $X$ to a partially ordered space $V$ satisfies

$$
P(x+y) \leqq P(x)+P(y)
$$

and

1 Theorem 2.3 and its proof are valid when $S$ is zero-dimensional. 


$$
P(t x)=t P(x)
$$

for all $x, y$ in $X$ and $t \geqq 0$.

A linear operator $T$ from $X$ to $V$ is dominated by $P$ if $T x \leqq P x$ for all $x$ in $X$. The set of all linear operators from $X$ to $V$ dominated by $P$ will be written $L(P)$.

2. Let $P$ be a sublinear function into $C(S)$, where $S$ is Stonean. We obtain a compact approximation to $L(P)$ by considering a finite partition $\mathscr{C}=\left\{U_{1}, \cdots, U_{M}\right\}$ of $S$ into disjoint open-and-closed sets. Let $C\left(S_{\varkappa}\right)$ denote the set of all function in $C(S)$ whose restrictions $f \mid U_{k}$ are constant. The constant values will be written as $f\left(U_{k}\right)$.

Lemma 2.1. Let $P$ be a sublinear function from a vector space $X$ to $C\left(S_{\varkappa}\right)$ and let $L\left(P_{z \ell}\right)$ be the set of all linear operators from $X$ to $C\left(S_{z c}\right)$ dominated by $P$. Then

$$
E L\left(P_{\mathscr{Z}}\right) \subseteq E L(P) \text {. }
$$

Proof. Suppose $T \in E L\left(P_{\mathscr{C}}\right)$. For $k=1, \cdots, M$ let $t_{k}$ be chosen arbitrarily in $U_{k}$. If $G, H \in L(P)$ and $T=1 / 2(G+H)$ define $G^{\prime}, H^{\prime} \in$ $L\left(P_{\mathscr{U}}\right)$ by

$$
G^{\prime} x=\sum_{k=1}^{M}(G x)\left(t_{k}\right) \chi_{k} \quad H^{\prime} x=\sum_{k=1}^{M} H x\left(t_{k}\right) \chi_{k}
$$

where $\chi_{k}$ is the characteristic function of $U_{k}$. Since $1 / 2\left(G^{\prime}+H^{\prime}\right)=T$ and $T \in E L\left(P_{\mathscr{r}}\right)$, we have $G^{\prime}=H^{\prime}=T$. Hence, for each $x \in X$ and $k=1, \cdots, M$,

$$
G^{\prime} x\left(U_{k}\right)=H^{\prime} x\left(U_{k}\right)=T x\left(U_{k}\right)
$$

so that

$$
G x\left(t_{k}\right)=H x\left(t_{k}\right)=T x\left(t_{k}\right) .
$$

Since $t_{k}$ was chosen arbitrarily in $U_{k}, G=H=T$. Hence $T \in E L(P)$.

Definition 2.2. Let $X$ and $E$ be linear topological spaces and let $\mathfrak{B}(X, E)$ be the space of all continuous linear operators from $X$ to $E$. The strong neighborhood topology for $\mathfrak{B}(X, E)$ is the topology with a base given by sets of the form

$$
N\left(T ; x_{1}, \cdots, x_{n} ; U\right)=\left\{S \in \mathfrak{B}(X, E):(T-S) x_{i} \in U, i=1, \cdots, n\right\}
$$

where $x_{1}, \cdots, x_{n} \in X$ and $U$ is a neighborhood of 0 in $E$.

If $E$ is normed, then we write 
$N\left(T ; x_{1}, \cdots, x_{n} ; \varepsilon\right) \quad$ for $N\left(T ; x_{1}, \cdots, x_{n} ; U\right)$ when $U$ is the open $\varepsilon$-ball about 0 .

Theorem 2.3. Let $\mathscr{W}$ be a finite partition of $S$ into nonempty open-and-closed subsets. Let $P$ be a sublinear function from a linear space $X$ into $C\left(S_{\mathscr{Y}}\right)$. Then $L(P)=\overline{\mathrm{co}} E L(P)$, with the closure in the strong neighborhood topology of $\mathfrak{B}(X, C(S))$.

Proof. Let $\mathscr{C}$ be any finite partition of $S$ into nonempty openand-closed sets. From Lemma 2.1, $\overline{\text { co }} E L(P) \supseteqq \overline{\text { co }} E L\left(P_{\ell}\right)$. Now $L\left(P_{u}\right)$ can be linearly identified with a certain compact convex subset of a finite product $X^{*} \times \cdots \times X^{*}$, where $X^{*}$ is the algebraic dual of $X$ with the topology $w\left(X^{*}, X\right)$. Hence, from the Krein-Milman Theorem, $\overline{c o} E L\left(P_{\mathscr{Z}}\right)=L\left(P_{\mathbb{Z}}\right)$.

Let $T \in L(P)$ and let $N\left(T ; x_{1}, \cdots, x_{n} ; \varepsilon\right)$ be a strong neighborhood of $T$. The functions $\left\{T x_{i}: i=1, \cdots, n\right\}$ are continuous so for each fixed $i$ there is a finite covering

$$
\mathscr{V}^{(i)}=\left\{V_{1}^{i} \cdots, V_{N_{i}}^{i}\right\}
$$

of $S$ by open sets such that

$$
\operatorname{Var}\left(T x_{i}, V_{k}^{i}\right)<\varepsilon
$$

for all $k$.

Since $S$ is zero-dimensional, there is a finite partition

$$
\mathscr{U}=\left\{U_{1}, \cdots, U_{M}\right\}
$$

of $S$ into nonempty open-and-closed sets that simultaneously refines $\mathscr{Y}^{(1)}, \cdots, \mathscr{Y}^{(n)}$. By taking a further refinement if necessary, $\mathscr{U}$ may also be assumed to be a refinement of $\mathscr{W}$ and then the functions $P(x)$ are constant on each of the sets $U_{k}$.

For each $k=1, \cdots, M$ define a sublinear functional $q_{k}$ on $X$ by $q_{k}(x)=\sup \left\{T x(t): t \in U_{k}\right\}$. From the Hahn-Banach Theorem, there exists a linear functional $\phi_{k}$ on $X$ dominated by $q_{k}$. Define $T_{1}: X \rightarrow C\left(S_{\varkappa}\right)$ by

$$
T_{1} x=\sum_{k=1}^{M} \phi_{k}(x) \chi_{U_{k}} .
$$

Then $T_{1} \in L\left(P_{\mathscr{U}}\right)$ and, for $i=1, \cdots, n$,

$$
\left\|\left(T_{1}-T\right) x_{i}\right\| \leqq \sup _{R} \operatorname{Var}\left(T x_{i}, U_{k}\right)<\varepsilon .
$$

Deduction of TheOREM 1.2. With $X$ and $S$ as in the statement of the theorem, let $\mathfrak{B}_{1}$ be the closed unit ball in $\mathfrak{B}(X, C(S))$. 
The set $\mathfrak{B}_{1}$ is $L(P)$, where $P$ is the sublinear function $P(x)=\|x\| e$, $e$ being the unit function in $C(S)$. By Theorem 2.3 $\mathfrak{B}_{1}=\operatorname{co} E \mathfrak{B}_{1}$ and the result for any closed ball then follows by a scalar multiplication and translation.

3. Nachbin's problem. Let $K$ be a closed bounded convex subset of a linear topological space $E$. Recall that $K$ has the positive binary intersection property if every pairwise-intersecting subfamily of

$$
\{x+\lambda K: x \in E, \lambda \geqq 0\}
$$

has nonempty intersection.

If $K$ is bounded and has the above property, it may be shown to. be centrally symmetric with a unique centre $c$, and to have the binary intersection property where the restriction $\lambda \geqq 0$ is removed. This is proved in [6].

Results in [4] and [2] then show that the set $K_{0}=K-c$ generates a subspace of $E$ which is a hyperconvex normed space and isomorphic to $C(S)$, with $S$ Stonean.

THEOREM 3.1. Let $E$ be a locally convex Hausdorff linear topological space containing a closed bounded convex subset $K$ with the positive binary intersection property. Let $p$ be a continuous sublinear functional on a locally convex Hausdorff linear topological space $X$.

If $L$ is the set of linear maps $T: X \rightarrow E$ such that for all $x$ in $X$

$$
T x \in \frac{1}{2}[p(x)-p(-x)] e+\frac{1}{2}[p(x)+p(-x)] K_{0}
$$

where $e$ is any extreme point of $K_{0}$, then $L=\overline{\text { co }} L$, with the closure taken in $\mathfrak{B}(X, E)$ with the strong neighborhood topology.

Proof. Because $p$ is continuous the set $L(P)$ is closed in the space $\mathfrak{B}(X, E)$ in the strong neighborhood topology. Since $K$ is centrally symmetric, $K_{0}$ has the binary intersection property and is linearly isomorphic to the unit ball in a space $C(S)$ with $S$ Stonean. The isomorphism may be chosen as in [4] so that $e$ is mapped onto the unit function of $C(S)$. Using $e$ to denote also this unit function, we may define a sublinear function $P(x)=p(x) e$ from $X$ to $C(S)$, which is the situation of Theorem 3.1. with $\mathscr{W}=\{S\}$.

Given $T \in L(P), x_{1}, \cdots, x_{n} \in X$ and $\varepsilon>0$ there exists $A \in \operatorname{co} E L(P)$ with 


$$
(T-A) x_{i} \in \varepsilon K_{0} \quad(i=1, \cdots, n) .
$$

Given a neighborhood $U$ of 0 in $E$, there exists $r>0$ with $K_{0} \subseteq r U$, since $K$ is bounded. So choosing $\varepsilon=r^{-1}$ there exists $A \in \operatorname{co} E L(P)$ with

$$
(T-A) x_{i} \in r^{-1} K_{0} \subseteq U \quad(i=1, \cdots, n),
$$

which completes the proof.

Deduction of THEOREM 1.1. (a) Let $p_{K}$ be the sublinear functional defined on $F^{*}$ by

$$
p_{K}(f)=\sup \{f(k): k \in K\} \text {. }
$$

Then, from the bipolar theorem,

$$
L=\left\{g \in F^{* *}: g(f) \leqq p_{K}(f) \text { for all } f \in F^{*}\right\}
$$

is identical with the canonical image $\hat{K}$ of $K$ under the evaluation map. Now apply Theorem 3.1 with $E=\mathbf{R}, K=[-1,1], e=1$ and $X=F^{*}$, taken with the topology of uniform convergence on compact. subsets of $F$. This shows that $\hat{K}$ is the closure of co $E \hat{K}$ in the topology $w\left(F^{* *}, F^{*}\right)$, which is equivalent to $K$ being the $w\left(F, F^{*}\right)$ and hence the strong closure of co $E K$ in $F$.

(b) Apply Theorem 3.1 with $X=\mathbf{R}$ and $E=F$. Then, under the natural isomorphism of $\mathfrak{B}(X, E)$ and $E, K_{0}$ corresponds to $L$, which satisfies $L=\overline{\text { co }} E L$. Since $E$ is a linear topological space we have

$$
K=\overline{\operatorname{co}} E K \text {. }
$$

\section{REFERENCES}

1. N. Aronszajn and P. Panitchpakdi, Extensions of unifomly continuous transformations and hyperconvex metric spaces, Pacific J. Math. 6 (1956), 405-439.

2. J. L. Kelley, Banach spaces with the extension property, Trans. Math. Soc. 72 (1952), $323-326$.

3. J. L. Kelley, I. Namioka, et al., Linear Topological Spaces, van Nostrand, 1963.

4. L. Nachbin, A theorem of the Hahn-Banach type for linear transformations, Trans. Amer. Math. Soc. 68(1950), 28-46.

5. - Some problems in extending and lifting continuous linear transformations, Proc. Int. Symposium on Linear Spaces, Jerusalem 1960, 340-350.

6. - Sur l'abondance des points extrémaux d'un ensemble convexe borné et fermé, Anais Acad. Brasileira Ciên. 34 (1962), 445-448.

Received August 11, 1969.

UNIVERSITY OF EXETER

U. K. 



\title{
PACIFIC JOURNAL OF MATHEMATICS
}

\section{EDITORS}

H. SAMELSON

Stanford University

Stanford, California 94305

C. R. HobвY

University of Washington

Seattle, Washington 98105

\section{J. DugunduI}

Department of Mathematics

University of Southern California

Los Angeles, California 90007

RICHARD ARENS

University of California

Los Angeles, California 90024

\section{ASSOCIATE EDITORS}
E. F. BECKENBACH
B. H. Neumann
F. WOLE
K. Yoshida

\section{SUPPORTING INSTITUTIONS}

\author{
UNIVERSITY OF BRITISH COLUMBIA \\ CALIFORNIA INSTITUTE OF TECHNOLOGY \\ UNIVERSITY OF CALIFORNIA \\ MONTANA STATE UNIVERSITY \\ UNIVERSITY OF NEVADA \\ NEW MEXICO STATE UNIVERSITY \\ OREGON STATE UNIVERSITY \\ UNIVERSITY OF OREGON \\ OSAKA UNIVERSITY \\ UNIVERSITY OF SOUTHERN CALIFORNIA
}

\author{
STANFORD UNIVERSITY \\ UNIVERSITY OF TOKYO \\ UNIVERSITY OF UTAH \\ WASHINGTON STATE UNIVERSITY \\ UNIVERSITY OF WASHINGTON

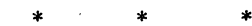 \\ AMERICAN MATHEMATICAL SOCIETY \\ CHEVRON RESEARCH CORPORATION \\ NAVAL WEAPONS CENTER
}

The Supporting Institutions listed above contribute to the cost of publication of this Journal, but they are not owners or publishers and have no responsibility for its content or policies.

Mathematical papers intended for publication in the Pacific Journal of Mathematics should be in typed form or offset-reproduced, (not dittoed), double spaced with large margins. Underline Greek letters in red, German in green, and script in blue. The first paragraph or two must be capable of being used separately as a synopsis of the entire paper. The editorial "we" must not be used in the synopsis, and items of the bibliography should not be cited there unless absolutely necessary, in which case they must be identified by author and Journal, rather than by item number. Manuscripts, in duplicate if possible, may be sent to any one of the four editors. Please classify according to the scheme of Math. Rev. Index to Vol. 39. All other communications to the editors should be addressed to the managing editor, Richard Arens, University of California, Los Angeles, California, 90024.

50 reprints are provided free for each article; additional copies may be obtained at cost in multiples of 50 .

The Pacific Journal of Mathematics is published monthly. Effective with Volume 16 the price per volume (3 numbers) is $\$ 8.00$; single issues, $\$ 3.00$. Special price for current issues to individual faculty members of supporting institutions and to individual members of the American Mathematical Society: $\$ 4.00$ per volume; single issues $\$ 1.50$. Back numbers are available.

Subscriptions, orders for back numbers, and changes of address should be sent to Pacific Journal of Mathematics, 103 Highland Boulevard, Berkeley, California, 94708.

PUBLISHED BY PACIFIC JOURNAL OF MATHEMATICS, A NON-PROFIT CORPORATION

Printed at Kokusai Bunken Insatsusha (International Academic Printing Co., Ltd.), 7-17, Fujimi 2-chome, Chiyoda-ku, Tokyo, Japan. 


\section{Pacific Journal of Mathematics}

\section{Vol. 36, No. $3 \quad$ BadMonth, 1971}

E. M. Alfsen and B. Hirsberg, On dominated extensions in linear subspaces of

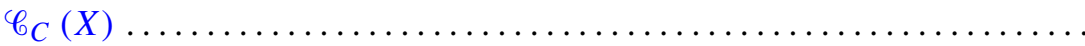

Joby Milo Anthony, Topologies for quotient fields of commutative integral

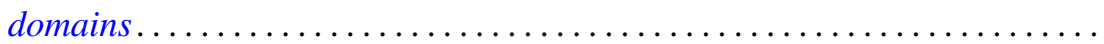

V. Balakrishnan, G. Sankaranarayanan and C. Suyambulingom, Ordered cycle lengths in a random permutation .......................... 603

Victor Allen Belfi, Nontangential homotopy equivalences............... 615

Jane Maxwell Day, Compact semigroups with square roots .............. 623

Norman Henry Eggert, Jr., Quasi regular groups of finite commutative nilpotent algebras .......................................... 631

Paul Erdős and Ernst Gabor Straus, Some number theoretic results ......... 635

George Rudolph Gordh, Jr., Monotone decompositions of irreducible Hausdorff continua .............................................

Darald Joe Hartfiel, The matrix equation $A X B=X \ldots \ldots \ldots \ldots \ldots \ldots . \ldots 69$

James Howard Hedlund, Expansive automorphisms of Banach spaces. II . . . . 671

I. Martin (Irving) Isaacs, The p-parts of character degrees in p-solvable

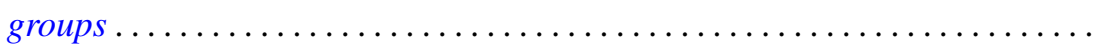

Donald Glen Johnson, Rings of quotients of $\Phi$-algebras ............... 693

Norman Lloyd Johnson, Transition planes constructed from semifield planes....

Anne Bramble Searle Koehler, Quasi-projective and quasi-injective modules.

James J. Kuzmanovich, Completions of Dedekind prime rings as second endomorphism rings...

B. T. Y. Kwee, On generalized translated quasi-Cesàro summability ...

Yves A. Lequain, Differential simplicity and complete integral closure

741

Mordechai Lewin, On nonnegative matrices.

753

Kevin Mor McCrimmon, Speciality of quadratic Jordan algebras ...

Hussain Sayid Nur, Singular perturbations of differential equations in abstract spaces .....................................

D. K. Oates, A non-compact Krein-Milman theorem .

Lavon Barry Page, Operators that commute with a unilateral shift on an invariant subspace...

Helga Schirmer, Properties of fixed point sets on dendrites.

Saharon Shelah, On the number of non-almost isomorphic models of $T$ in a

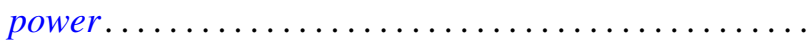

Robert Moffatt Stephenson Jr., Minimal first countable Hausdorff spaces....

Masamichi Takesaki, The quotient algebra of a finite von Neumann algebra 